Research Article

\title{
Study on Consumption of Fast-food among Medical Students of UPUMS, Saifai, Etawah
}

\author{
Ajay Kumar Prajapati', Vineet Kumar ${ }^{2}$, Kanchan Soni ${ }^{3}, \underline{\text { Naresh Pal Singh }}{ }^{4}$, \\ Dhiraj Kumar Srivastava ${ }^{5}$ Ruchi $^{6}$
}

${ }^{1,2,3}$ Post Graduate Junior Resident, ${ }^{4}$ Professor, ${ }^{5}$ Associate Professor, Department of Community Medicine, Uttar Pradesh University of Medical Sciences, Saifai, Etawah, Uttar Pradesh, India.

${ }^{6}$ BAMS, Chaudhary Brahm Prakash Ayurved Charak Sansthan, Najafgarh, New Delhi, India.

DOI: https://doi.org/10.24321/2394.6539.202107

$\begin{array}{llll}\text { I } & \mathbf{N} & \mathbf{F} & \mathbf{O}\end{array}$

\section{Corresponding Author:}

Ajay Kumar Prajapati, Department of Community Medicine, Uttar Pradesh University of Medical Sciences, Saifai, Etawah, Uttar Pradesh, India. E-mail Id:

ajayprajapati112@gmail.com

Orcid Id:

https://orcid.org/0000-0001-7859-5575

How to cite this article:

Prajapati AK, Kumar VK, Soni K, Singh NP, Srivastava DK, Ruchi. Study on Consumption of Fast-food among Medical Students of UPUMS, Saifai, Etawah. J Adv Res Med Sci Tech. 2021;8(3):1-4.

Date of Submission: 2021-06-27

Date of Acceptance: 2021-08-12
$\begin{array}{llllllll}\mathbf{A} & \mathbf{B} & \mathbf{S} & \mathbf{T} & \mathbf{R} & \mathbf{A} & \mathbf{C} & \mathbf{T}\end{array}$

Background: Fast-food is food that is prepared and served quickly at outlets called fast-food outlets. It is high in calories and lacks micronutrients. It has been proved that its intake leads to many diseases and disorders like obesity which is likely to cause cardiovascular diseases later on. Fast-food culture is a vigorously uprising trend among the youngsters and medical students are no exception to it.

Objectives: 1). To determine the burden of Fast-food consumption among medical students. 2). To assess the pattern and associated factors for Fast-food consumption among study subjects.

Methods: A cross-sectional study was done among all the undergraduate medical students studying at UPUMS, Saifai, Etawah. A pre-designed pretested structured questionnaire was used to collect information regarding their socio-demographic profile, pattern of fast-food consumption, and various factors which promoted the consumption of Fast-food among students. The data thus collected were analyzed using SPSS software Version 25.0.

Results: Out of 800 undergraduate students pursuing MBBS at UPUMS, Saifai, only 620 students could be contacted for data collection. 26 forms were rejected as the data was incompletely filled. Hence, data of 594 students were entered into excel sheet and analyzed.

Conclusions: Out of 594 students, 524 (88.2\%) students were aware of the fact that consuming fast-food leads to many diseases and disabilities, while 20 (3.3\%) students did not know its adverse effect. Study shows that consumption behaviour of Fast-food does not depend on age or gender of the people, rather it highly depends on its taste and pocket money of the consumer.

Keywords: Fast-food, Medical Students, Obesity 


\section{Introduction}

Both Fast-food and junk foods are defined in many ways in various dictionaries. Fast-food is a type of food that we get from a restaurant designed to deliver the order in the quickest possible way. Junk food is food with extremely low nutritional value, sometimes called rich in 'empty calories.' ${ }^{1}$ Fast-food consumption has been dramatically increasing in both the developed and underdeveloped countries for the past 15 years. Junk food normally contributes low micronutrients to the diet, contains large amounts of fat and/or sugar, and is high in energy. It helps to provide some calories for the body, but the usual and frequent use of junk food is harmful to human beings. Therefore, food like Fastfood, soft drinks, sweets, salty sweets, and snacks are junk food. Fast-food is a food that is prepared and served quickly, easily accessible, and cheap alternative to home-cooked meals. ${ }^{2}$ It includes chips, sandwiches, burgers, pizza, etc. It is high in calories and lacks micronutrients. It has been proved that its intake leads to many diseases and disorders like obesity which is likely to cause cardiovascular diseases such as hypertension, dyslipidemia, and type-2 diabetes later on. ${ }^{3}$ Fast-food culture is a vigorously uprising trend among youngsters and medical students. ${ }^{4}$

However, stressful life of students owing to increased study load, tight schedule of classes and assignments negatively influences choice of food because Fast-food is conveniently available and can save more time of medical students. ${ }^{5}$

\section{Aim}

To find out burden and pattern of Fast-food consumption among medical students.

\section{Objectives}

- To determine the burden of Fast-food consumption among medical students

- To assess the pattern and associated factors for Fastfood consumption among study subjects

\section{Material and Methods}

A cross-sectional study design was conducted among all the undergraduate medical students studying at Uttar Pradesh University of Medical Sciences (UPUMS), Saifai, Etawah, Uttar Pradesh. All undergraduate students studying in the medical college were taken as study participants. The duration of the study was one month (15th September 2020 to 15th October 2020). Total 800 undergraduate medical students have been pursuing MBBS at UPUMS. Study participants were interviewed using a pre-designed, pre-tested, semi-structured questionnaire to collect information regarding their socio-demographic profile, pattern of the fast-food consumption along the factors which promoted them to consume Fast-food. The data thus collected was entered into a Microsoft-Excel spreadsheet and was analyzed using IBM SPSS software Version 25.0. Continuous data were summarized using mean, median, and standard deviation depending on the distribution of the data. Categorical data were summarized using percentages and proportions. Ethical Clearance for the research was taken from the Ethical Committee of UPUMS, Saifai before starting the study. Written informed consent was taken from all the study participants after explaining the purpose, nature, and procedure of the study.

\section{Result}

Out of 800 undergraduate medical students pursuing MBBS at UPUMS, Saifai only 620 students could be contacted for data collection. 26 forms were rejected as the data was incompletely filled. Hence, data of 594 students was entered into excel sheet and analyzed. The study showed that all the respondents consumed Fast-food; 379 (63.8\%) were males and $215(36.2 \%)$ females. All of them were residing in the hostel within the campus. The mean ages of students were $21.7+1.8$ years. It was found that $85(14.3 \%)$ of students were overweight, 37 (6.2\%) were underweight (Table 1).

Table 2 illustrates the pattern of Fast-food consumption. It was found that the most preferred Fast-food was fried chicken 151 (25.4\%) followed by 147 (24.7\%) samosa, 85 (14.3\%) pizza, 63 (10.6\%) burger and 39 (6.5\%) chowmein and while the most preferred beverage was tea/coffee 176 (29.6\%) followed by 162 (27.3\%) fruit juice, 104 (17.5\%) carbonated drink and 99 (16.7\%) milk shake.

When asked about the frequency of Fast-food consumption in a week among the students, it was found that 146 (24.6\%) consumed Fast-food once a week, 136 (22.9\%) consumed Fast-food thrice a week and $69(11.6 \%)$ consumed Fastfood daily. Most of them 494 (83.2\%) students consumed Fast-food mostly during evening.

Table I.BMI of the Subjects

\begin{tabular}{|c|c|c|c|c|c|c|c|}
\hline \multirow[b]{2}{*}{ Sex } & \multicolumn{6}{|c|}{ Observed BMI ( Body Mass Index ) of Students } & \multirow[b]{2}{*}{ Total } \\
\hline & $\begin{array}{c}\text { Under weight } \\
\quad(<18.5)\end{array}$ & $\begin{array}{c}\text { Normal range } \\
(18.5-24.9)\end{array}$ & $\begin{array}{l}\text { Over weight } \\
(25.0-29.9)\end{array}$ & $\begin{array}{c}\text { Obese Class-I } \\
(30.0-34.9)\end{array}$ & $\begin{array}{c}\text { Obese Class-II } \\
(35.0-39.9)\end{array}$ & $\begin{array}{c}\text { Obese Class-III } \\
(\geq 40)\end{array}$ & \\
\hline Male & 5 & 310 & 56 & 6 & 2 & - & 379 \\
\hline Female & 32 & 145 & 29 & - & 8 & 1 & 215 \\
\hline Total & $37(6.2 \%)$ & $455(76.6 \%)$ & $85(14.3 \%)$ & $6(1.0 \%)$ & 10 (1.6\%) & 1 (0.1\%) & 594 \\
\hline
\end{tabular}


Table 2.Patterns of Fast Food Consumption

\begin{tabular}{|c|c|c|c|c|}
\hline S. No. & Variables & Food Items & Number of students & Total (\%) \\
\hline \multirow{7}{*}{1.} & \multirow{7}{*}{ Preferred Fast-food } & Pizza & 85 & 14.3 \\
\hline & & Burger & 63 & 10.6 \\
\hline & & Fried chicken & 151 & 25.4 \\
\hline & & Samosa & 147 & 24.7 \\
\hline & & Chowmein & 39 & 06.5 \\
\hline & & Others & 61 & 10.2 \\
\hline & & All of these & 48 & 08.0 \\
\hline \multirow{6}{*}{2.} & \multirow{6}{*}{ Preferred beverage } & Carbonated drink & 104 & 17.5 \\
\hline & & Fruit juice & 162 & 27.3 \\
\hline & & Milk shake & 99 & 16.7 \\
\hline & & Tea/coffee & 176 & 29.6 \\
\hline & & Other & 11 & 01.9 \\
\hline & & All of these & 42 & 07.0 \\
\hline \multirow{5}{*}{3.} & \multirow{5}{*}{$\begin{array}{l}\text { Time of consumption of Fast- } \\
\text { food }\end{array}$} & Breakfast & 38 & 08.0 \\
\hline & & Lunch & 7 & 01.2 \\
\hline & & Evening & 494 & 83.2 \\
\hline & & Dinner & 37 & 06.2 \\
\hline & & All & 18 & 03.0 \\
\hline \multirow{6}{*}{4.} & \multirow{6}{*}{$\begin{array}{l}\text { Frequency of Fast-food } \\
\text { consumption }\end{array}$} & 1 times/wk & 146 & 24.6 \\
\hline & & 2 times/wk & 112 & 18.9 \\
\hline & & 3 times/wk & 136 & 22.9 \\
\hline & & 4 times/wk & 65 & 10.9 \\
\hline & & $>5$ times/wk & 66 & 11.1 \\
\hline & & Daily & 69 & 11.6 \\
\hline
\end{tabular}

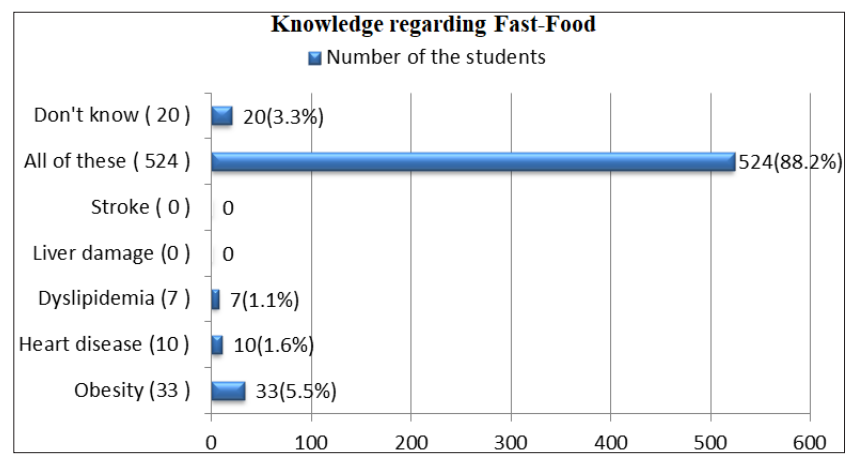

Figure I.Bar Diagram Showing the Knowledge regarding Fast-food Disorders and Disease

Despite, most of 524 (88.2\%) students were aware of the fact that consuming fast-food leads to many diseases and disabilities, while $20(3.3 \%)$ students did not know its ill-effect on health (Figure-1). All the subjects consumed Fast-food mostly because they found it tasty. Other factors for consuming Fast-food were mess closed 96 (16.1\%), lack of cooking 72 (12.1\%), and also to save time $32(5.4 \%)$.

\section{Discussion}

Based on the results of this present study, the majority of $379(65.8 \%)$ of the respondents are male students. It can be concluded that male students are more likely to consume fast-food than female students i.e. 215 (36.2\%). Similar study conducted by Lassen et al. ${ }^{6}$ at University of Ankara,
Turkey, to determine the habits of fast-food consumption among university students concluded that 401 respondents, $74.0 \%$ female students and $26.0 \%$ male students, were consuming fast-food. In the present study, most of them consumed Fast-food because they found it tasty. Other factors for consuming Fast-food are mess closed 96 (16.1\%), lack of cooking 72 (12.1\%) and also to save time 32 (5.4\%). Another study conducted by Khongrangjem et $\mathrm{al}^{7}$ found that behavior of students in consuming Fast-food was due to its affordability at low price, great taste, convenience. The results also showed that $72.0 \%$ of the respondents believed that the prices of Fast-food were at a moderate level, which was essentially affordable. Jayasinghe et $a^{8}{ }^{8}$ in a study reported that more than $80 \%$ of Nigerian university students eat Fast-food at least once a week. Current study revealed that $146(24.6 \%)$ consumed Fast-food once a week, 136 (22.9\%) consumed Fast-food thrice a week and $69(11.6 \%)$ consumed Fast-food daily.

\section{Conclusion}

The trend of Fast-food consumption among the students has been increasing in the recent years. Findings of the study show that consumption behaviour of students does not depend on age or gender of the people, rather it highly depends on its taste and pocket money of the consumer. Although consumption of Fast-food adversely affects the health of the students and can lead to obesity, heart disease, 
and low immunity, present study showed that most students were aware of the fact that consuming fast leads to many diseases and disabilities, while 20 (3.3\%) students did not know its adverse effect.

\section{Recommendations}

Awareness programme and proper policy measures should be undertaken so that the consumption of the Fast-food can be minimized in the coming years. Healthy food rich in nutrients and minerals are recommended. Health education programs are recommended to promote healthy lifestyles and dietary habits among medical students. It must be remembered that the addiction to 'fast-food' is great for business. It is all in our hands to choose junk food or health.

\section{Conflict of Interest: None}

\section{References}

1. Foodtolive [Internet]. Fast-food and junk food: Is there any difference? [cited 15 June 2021]. Available from: https://foodtolive.com/healthy-blog/fast-food-junkfood-difference/.

2. NIH [Internet]. NIH study finds heavily processed foods cause overeating and weight gain [cited 15 June 2021]. Available from: https://www.nih.gov/news-events/ news-releases/nih-study-finds-heavily-processedfoods-cause-overeating-weight-gain.

3. World Health Organization [Internet]. Life Course Perspective of Coronary Heart Disease, Stroke and Diabetes [cited 15 June 2021]. Available afromt: https:// apps.who.int/iris/handle/10665/67173.

4. Kaushik JS, Narang M, Parak A. Fast-food consumption in children. Indian Pediatr. 2011;48;97-101.

5. De PA, Bassett N, Rossi A, Sammán N. Trends in food consumption of university students. Nutr Hosp. 2015 Apr 1; 31(4):1824-31. [Google Scholar]

6. Lassen AD, Lehmann C, Andersen EW, Werther M N, Thorsen AV, Trolle E, Gitte G, Tetens I. Gender differences in purchase intentions and reasons for meal selection among Fast-food customers-Opportunities for healthier and more sustainable Fast-food. Food qual and pref. 2016;47:123-129. [Google Scholar]

7. Khongrangjem T, Dsouza SM, Prabhu P, Dhange VB, Pari V, Ahirwar SK, Sumit K. A study to assess the knowledge and practice of Fast-food consumption among PreUniversity students in Udupi Taluk, Karnataka, India. Clin Epidem and Global Health. 2018;6(4):172-175. [Google Scholar]

8. Jayasinghe JMJK, De Silva LPU. Fast-food consumption and health status of students of a university in Sri lanka. journal of food and agriculture. 2014;7(1-2): 38-50. [Google Scholar] 